Military Technical College Kobry El-Kobbah, Cairo, Egypt

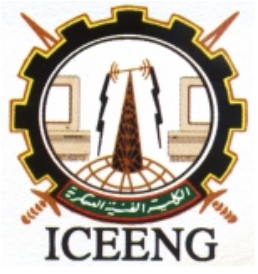

\author{
$7^{\text {th }}$ International Conference \\ on Electrical Engineering \\ ICEENG 2010
}

\title{
Experimental Natural Prints And The Re-Calculated General Equations Of The Electrical Parameters For Buried Bare Pipe -Soil- Earth System With And Without Applying Cathodic Protection System
}

\author{
By
}

\section{Ashraf Abdelraouf Mohamed Fouad Ahmed}

\section{$\underline{\text { Abstract: }}$}

The rate of discharge through the stray electrolytic capacitor between the pipe and the remote earth is to be considered as the corrosion current. The electrochemical properties of the soil, which are the soil resistivity of the soil volume, the relative permittivity of the soil layer around the pipe and the chemical properties which could be considered as the $\mathrm{pH}$ of the soil film layer around the pipe, are affected directly by the humidity change. When considering the room temperature and by neglecting the effect of $\mathrm{CO}_{2}$ content in the soil, these values of the electrochemical properties of any soil returns back to its initial conditions after soil dryness to its initial condition. This means that corrosion rate will also be changed during the humidity change around the pipe segment. So, when considering the fact that the pipeline will not be changed or replaced and the surrounding medium around it will not be changed or replaced by another kind of soil, then the behavior of the electrical parameters (stray electrolytic capacitance, stray potential, surface created charge) of the pipe-soil-earth system will act as a print of this combination of this pipe and this soil. This paper recalculates the general form of the equations of the electric parameters and obtains the print curves \& constants at natural condition with and without applying cathodic protection system in terms of the electrochemical properties around the pipe. The average error reduced to be less than \pm $5 \%$. This will help to study both the corrosion problem and cathodic protection by an electric concept with an electric analogue circuit which is the aim of this study.

\section{Keywords:}

Electrical study of pipe - soil - earth system 


\section{Introduction:}

At humidity equal to zero, the soil medium around pipeline could be considered as a dielectric material which has its relative permittivity. If the humidity is increased, the soil medium is considered to be as an electrolyte associated with a change happened in the values of the relative permittivity, resistivity and $\mathrm{pH}$ of the soil. These changes which happened in soil electrochemical properties will continue by increasing the humidity but these values will return back to their original values, or nearby initial values, after the humidity returns back to its initial value. The change of the soil medium between isolation medium and conduction medium according to the percentage of the humidity could be studied electrically. Then, based on the new proposed electrical concept of corrosion which state that: "Due to surrounding medium effect around metal structure buried in the ground, the charge created on metal o.s.a builds up a potential through an electrolytic stray capacitor between metal o.s.a and an imaginary coaxial earthing cylinder " [1][2], The proposed electric concept of corrosion is depending on the concept of the positive charge created on the outer surface area (o.s.a) of the buried bare pipe line segment due to the building up potential between the pipe and the remote earth. The created charge is dissipated to the surrounding medium (corrosion process) through a stray electrolytic capacitor between the pipe and an imaginary coaxial earthing cylindrical.

In case of coated pipe segment, the dielectric constant of the soil $\mathrm{K}_{\mathrm{S}}$ acts with the dielectric constant of the pipe coating material $\mathrm{K}_{\mathrm{C}}$ as a coaxial cylindrical capacitor with compound dielectric. As $\mathrm{K}_{\mathrm{C}}$ of the coating material is decreased, the total capacitance is decreased (two capacitors are in series) then charge $\mathrm{Q}=\mathrm{C} \times \mathrm{V}$ is decreased .That's to say that corrosion process is decreased. If deterioration of coating material occurred, then $\mathrm{K}_{\mathrm{C}}$ is increased. That's to say that the total capacitance of the compound dielectric is increased .This means that the corrosion process is increased as the created charge on metal outer surface area $\mathrm{Q}=\mathrm{C} \times \mathrm{V}$ will be increased [1][2].

In other words, if two dissimilar electrodes buried in a box which is containing a soil medium, a circulating current will take place between these electrodes due to the difference in electrodes' natural potential while a capacitance in nano farad could be measured between these two dissimilar electrodes (through the soil). The potential difference, the capacitance and the corrosion current between the positive electrode and the negative electrode are electric quantities. Then, it may be possible to understand the corrosion and cathodic protection by an electrical concept beside the electrochemical and thermodynamic concepts.

The corrosion may be described electrically (electrons losses) by the equation: $\mathrm{Q}=\mathrm{C} *$ $\mathrm{V}$, while the rate of discharge $\mathrm{dQ} / \mathrm{dt}$ is equal to the corrosion current from the $+\mathrm{ve}$ 
electrode to the -ve one [1] [2].

The same concept could be applied on the system of buried pipeline and the surrounding soil medium. The pipeline may be considered the +ve electrode while the remote earth may be considered the -ve electrode. In case of pipe-soil-earth system that it is not subjected to any external interference, if it is possible to find a correlation between the electrical parameters and the electrochemical properties of the soil at different humidity with and without applying cathodic protection system, then the result will be considered as an electrical print or as a data sheet of this pipe-soil-earth system. These electrical prints will be recalculated if any essential values are changed in the pipe-soil-earth system. The importance of these electrical prints are to define both the electrical parameters and the cathodic protection level of any buried pipe segment of the pipe-soilearth system if the protection current and the electrochemical properties are measured at the pipe segment directly from the field.

Now, as the electrochemical properties of any soil are changed by the change of humidity but returns back to its initial conditions after some time required for soil dryness, we can define a new factor named the soil factor as: "The soil factor $\left(\mathrm{S}_{\mathrm{f}}\right)$ is the instantaneous value of the electro-chemical properties of the soil based on the electrical properties at Humidity equal to $10 \%$ "[1] [2] and is equal to:

$$
\mathrm{S}_{\mathrm{f}}=\left(1 / \mathrm{K}_{\mathrm{S}}\right) \mathrm{pHH} \log \rho \quad \text { at room temperature }
$$

Dimension of $\left[\mathrm{S}_{\mathrm{f}}\right]=\left[1 / \mathrm{K}_{\mathrm{S}}\right][\mathrm{pH}][\mathrm{H}][\log \rho]=. \mathrm{m} \%$

Where:

$$
\begin{aligned}
& \mathrm{S}_{\mathrm{f}}=\text { soil factor } \quad . \mathrm{m} \% \\
& \mathrm{~K}_{\mathrm{S}}=\text { dielectric constant of the soil at } \mathrm{H}=10 \% \\
& \mathrm{pH}=\text { power of Hydrogen of the soil } \\
& \mathrm{H}=\text { humidity of the soil \% } \\
& \rho=\text { soil resistivity in } . m \text { at } \quad \mathrm{H}=10 \%
\end{aligned}
$$

The importance of the soil factor is that it is combining all parameters which can affect directly on the cathodic protection level or in corrosion process. Such factors which can be obtained by a direct measurements from the field. This means that if it is possible to study the relationship between the soil factor and the electrical parameters of the bare pipe segment, then the print curves and the print constants of the electrical parameters of the pipe-soil-earth system could be obtained at natural condition with and without applying cathodic protection system. The soil factor can be considered to be as the key of many studies based on the new proposed electrical concept of corrosion. For an example, the general equation of the natural stray capacitance between external surface area of bare pipe segment and earth is obtained in terms of the soil factor with an 
average error $\pm 30 \%$ and its print curves and constants are obtained for pipe-soil system for 10 different soils [3]. Also, the general equation of both the natural stray potential and the natural created charge are obtained in terms of the soil factor with an average error $\pm 30 \%$ and their print curves and constants are obtained for pipe-soil system for 10 different soils [4] [5]. In this paper, we will continue to use the soil factor, to complete such study concerning the natural electrical parameters of pipe-soil-earth system with and without applying cathodic protection system to reduce the average error of the equations of electrical parameters to be less than $\pm 5 \%$.

\section{Case1:}

\subsection{Pipe - Soil - Earth System Without C.P System}

\subsubsection{The Experiment}

At natural condition system without any influence of any external systems such as cathodic protection systems, pipe crossing.... (only bare pipe + soil + point earth), the experiment is consisting of a system with bare pipe segment $(2.1 \mathrm{~cm}$ diameter, $1 \mathrm{~mm}$ thickness and $31.1 \mathrm{~cm}$ length), buried in a soil with humidity equal to $10 \%$ and the soil have soil resistivity equal to $\rho . \mathrm{m}$, soil power of hydrogen $\mathrm{pH}$ and soil relative permittivity $\mathrm{K}_{\mathrm{s}}$. Table 1 shows the different kind of soils used in this experiment and the range of humidity.

Table 1: 10 different kind of soil and operating range of $H \& p H$

\begin{tabular}{|c|c|c|c|c|c|c|c|c|c|c|c|}
\hline \multicolumn{2}{|c|}{ Kind of soil } & $\rho_{1}$ & $\boldsymbol{\rho}_{2}$ & $\rho_{3}$ & $\rho_{4}$ & $\rho_{5}$ & $\rho_{6}$ & $\rho_{7}$ & $\rho_{8}$ & $\rho_{9}$ & $\rho_{10}$ \\
\hline \multicolumn{2}{|c|}{ Box under test } & 1 & 4 & 9 & 10 & 13 & 18 & 19 & 24 & 27 & 28 \\
\hline Resistivity & $\mathbf{m}$ & 31 & 37 & 43 & 62 & 125 & 138 & 1382 & 2010 & 5654 & 7539 \\
\hline \multicolumn{2}{|c|}{$\begin{array}{c}\text { Relative } \\
\text { permittivity } K_{S}\end{array}$} & 138 & 66 & 86 & 43 & 51 & 274 & 22 & 154 & 43 & 355 \\
\hline \multirow{2}{*}{$\begin{array}{c}\text { Humidity } \\
\%\end{array}$} & Start & 6 & 8 & 5 & 10 & 6 & 5 & 5 & 5 & 5 & 10 \\
\hline & End & 60 & 85 & 100 & 100 & 100 & 100 & 96 & 80 & 100 & 100 \\
\hline \multirow[t]{2}{*}{ pH } & Start & 7.8 & 7.3 & 7.8 & 7.8 & 7.3 & 7.6 & 7.2 & 7 & 7.2 & 6.7 \\
\hline & End & 7 & 6.5 & 6 & 6 & 5 & 5 & 5.3 & 7 & 6 & 7 \\
\hline
\end{tabular}

When considering the system pipe-soil-earth for ten different kind of soil as shown in table 1, the test procedures are as follow: 
1) Calculate the value of the soil factor according to the eq. 1 :

2) Measure both the stray potential $V_{P-P E}$, the stray capacitance $C_{P-P E}$ and the correspondent pipe to soil potential $\mathrm{V}_{\mathrm{H}-\mathrm{C}}$ by using $\mathrm{Cu} / \mathrm{CuSO}_{4}$ half cell. Calculate total surface charge $\mathrm{Q}=\mathrm{V}_{\mathrm{P}-\mathrm{PE}} * \mathrm{C}_{\mathrm{P}-\mathrm{PE}}$

3) Increase the Humidity and calculate the new value of the soil factor.

4) Repeat steps $2 \& 3$ until humidity around the pipe segment reaches its maximum as shown in table 1.

5) Change this type of soil by another kind of soil and repeat all the steps done before.

6) Repeat again the steps for 10 different kind of soil shown in table 1 .

7) Build up the results table.

\subsubsection{The Results}

If we plot the measured electric quantity (natural stray potential $\mathrm{V}_{\mathrm{P}-\mathrm{PE}}$, natural stray capacitance $\mathrm{C}_{\mathrm{P}-\mathrm{PE}}$ and surface total charge $\mathrm{Q}$ ) individually as $\mathrm{y}$ axis in terms of the correspondent measured soil factor as $\mathrm{x}$ axis, we will obtain such following curves as shown in figures $1 \& 2$. Except box 4 and box 13, the curves and equations show eight boxes which could be expressed by a $4^{\text {th }}$ degree polynomial equation with an average error equal to zero percent. Table 2 shows the error table for the 10 different soil resistivity.

Table 2: Error table for 10 different kinds of soil and operating range of Humidity

\begin{tabular}{|c|c|c|c|c|c|c|c|c|c|c|c|}
\hline \multicolumn{2}{|c|}{ Kind of soil } & $\rho_{1}$ & $\rho_{2}$ & $\rho_{3}$ & $\rho_{4}$ & $\rho_{5}$ & $\rho_{6}$ & $\rho_{7}$ & $\rho_{8}$ & $\rho_{9}$ & $\rho_{10}$ \\
\hline \multicolumn{2}{|c|}{ Box under test } & 1 & 4 & 9 & 10 & 13 & 18 & 19 & 24 & 27 & 28 \\
\hline \multicolumn{2}{|c|}{$\begin{array}{c}\text { Polynomial } \\
\text { degree }\end{array}$} & $4^{\text {th }}$ & $4^{\text {th }}$ & $4^{\text {th }}$ & $4^{\text {th }}$ & $4^{\text {th }}$ & $4^{\text {th }}$ & $4^{\text {th }}$ & $4^{\text {th }}$ & $4^{\text {th }}$ & $4^{\text {th }}$ \\
\hline \multicolumn{2}{|c|}{$\mathrm{V}_{\text {P-PE }}$ Error \% } & 0 & \pm 30 & 0 & 0 & 0 & 0 & 0 & 0 & 0 & 0 \\
\hline \multicolumn{2}{|c|}{$\mathrm{C}_{\mathrm{P}-\mathrm{PE}}$ Error \% } & 0 & \pm 30 & 0 & 0 & \pm 20 & 0 & 0 & 0 & 0 & 0 \\
\hline \multicolumn{2}{|c|}{$\mathbf{Q}_{\text {тот. Error \% }}$} & 0 & \pm 50 & 0 & 0 & \pm 25 & 0 & $\underline{0}$ & 0 & 0 & 0 \\
\hline \multirow{2}{*}{$\begin{array}{c}\text { Humidity } \\
\%\end{array}$} & Start & 6 & 8 & 5 & 10 & 6 & 5 & 5 & 5 & 5 & 10 \\
\hline & End & 60 & 85 & 100 & 100 & 100 & 100 & 96 & 80 & 100 & 100 \\
\hline
\end{tabular}

\subsection{Electrical Parameters Print Curves For Pipe - Soil -Earth Under Test}

By considering the measured soil factor as $\mathrm{x}$ axis against the measured electrical

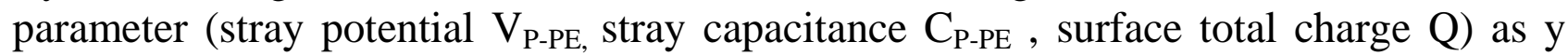
axis, the next following print curves were obtained for the pipe - soil - earth systems under test as shown in figures $1 \& 2$. The stray capacitance is illustrated by group a, 
figures $1 \mathrm{a} \& 2 \mathrm{a}$. The stray potential is illustrated by group $\mathrm{b}$, figures $1 \mathrm{~b} \& 2 \mathrm{~b}$.. The surface total charge is illustrated by group c, figures $1 \mathrm{c} \& 2 \mathrm{c}$.. All points resulting from the experiment could be represented by a trend line for each measured electric quantity and could be represented by a PRINT for each pipe-soil-earth under test, with $4^{\text {th }}$ degree polynomial equation. The average error for all equations is less than $\pm 5 \%$. The above result is very important. This proves that it may be possible to complete this electrical study of pipe-soil-earth system to find an electric circuit diagram of this combination of pipe segment-soil-earth system which is the real target. This means that, beside the electrochemical and thermodynamic concepts of corrosion, it is possible to have an electric concept of the corrosion process and to convert both the corrosion and cathodic protection problems into an electric problem.

\section{$\underline{\text { 2.3 Stray Potential General Equation For Pipe - Soil - Earth Under Test }}$}

For each soil under test and from natural stray potential curves and equations, it can easily observe that the general equation of the natural stray potential from pipe segment to the remote earth during humidity change is a $4^{\text {th }}$ degree polynomial equation which is function of the soil factor, $V_{n \text { stray }}=f\left(X=S_{f}\right)$. For each soil under test, the general stray potential equation is function of the measured soil factor $V_{n \text { stray }}=f\left(X=S_{f}\right), 4^{\text {th }}$ degree polynomial. The stray potential general equation is given by Eq.2:

Where:

$$
\mathbf{V}_{n \text { stray }}=\mathrm{A}_{4 \mathrm{vn}} \mathbf{X}^{4}+\mathrm{A}_{3 \mathrm{vn}} \mathbf{X}^{3}+\mathrm{A}_{2 \mathrm{vn}} \mathbf{X}^{2}+\mathrm{A}_{1 \mathrm{vn}} \mathbf{X}+\mathrm{A}_{0 \mathrm{vn}}
$$

$\mathrm{A}^{\prime} \mathrm{s}:=\mathrm{A}_{() \mathrm{v}}$ are the natural stray potential print constants of the pipe soil under test

$\mathbf{X}=$ is the value of the soil factor at certain humidity

\section{$\underline{\text { 2.4 Stray Capacitance General Equation For Pipe - Soil - Earth Under Test }}$}

For each kind of soil under test and from stray capacitance curves and equations, it can easily observe that the general equation of the stray capacitance, at natural condition without applying cathodic protection, to the remote earth during humidity change is a $4^{\text {th }}$ degree polynomial equation which is function of the soil factor, $\mathrm{C}_{\mathrm{n} \text { stray }}=\mathrm{f}$ (soil factor $\mathbf{X}$ ) For each soil under test, the general stray capacitance equation is function of the measured soil factor, $\mathrm{C}_{\text {stray }}=\mathrm{f}\left(\mathrm{X}=\mathrm{S}_{\mathrm{f}}\right), 4^{\text {th }}$ degree polynomial. The stray capacitance general equation is equal to Eq. 3 :

Where:

$$
\mathbf{C}_{\mathbf{n} \text { stray }}=\mathrm{A}_{4 \mathrm{cn}} \mathbf{X}^{\mathbf{4}}+\mathrm{A}_{3 \mathrm{cn}} \mathbf{X}^{\mathbf{3}}+\mathrm{A}_{2 \mathrm{cn}} \mathbf{X}^{\mathbf{2}}+\mathrm{A}_{1 \mathrm{cn}} \mathbf{X}+\mathrm{A}_{0 \mathrm{cn}}
$$

A's: $=\mathrm{A}_{() \mathrm{CN}}$ are the stray capacitance print constants of the pipe soil under test

$\mathbf{X}=$ is the value of the soil factor at certain humidity 

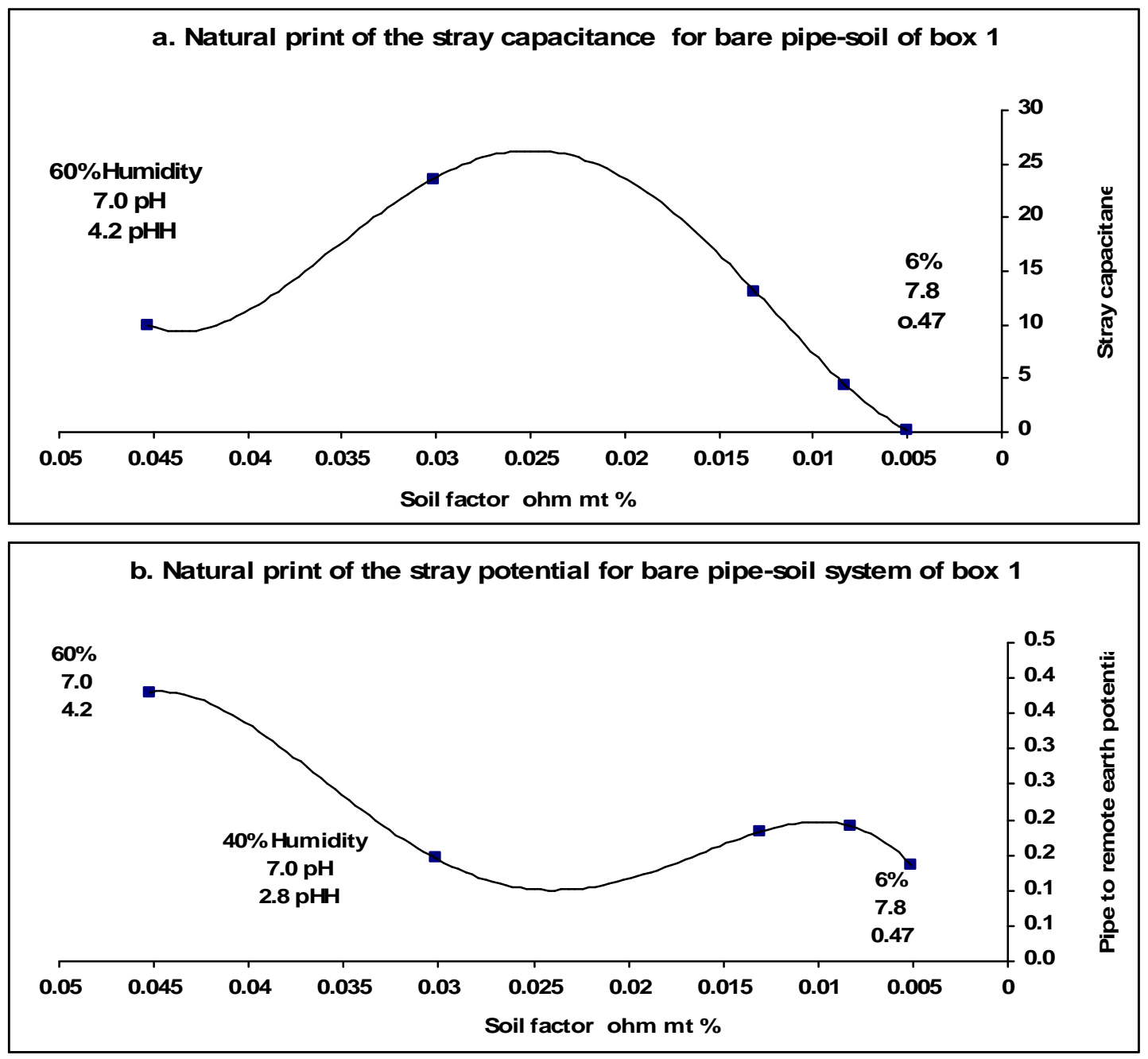

c. Natural print of the surface charge for bare pipe-soil system of box 1

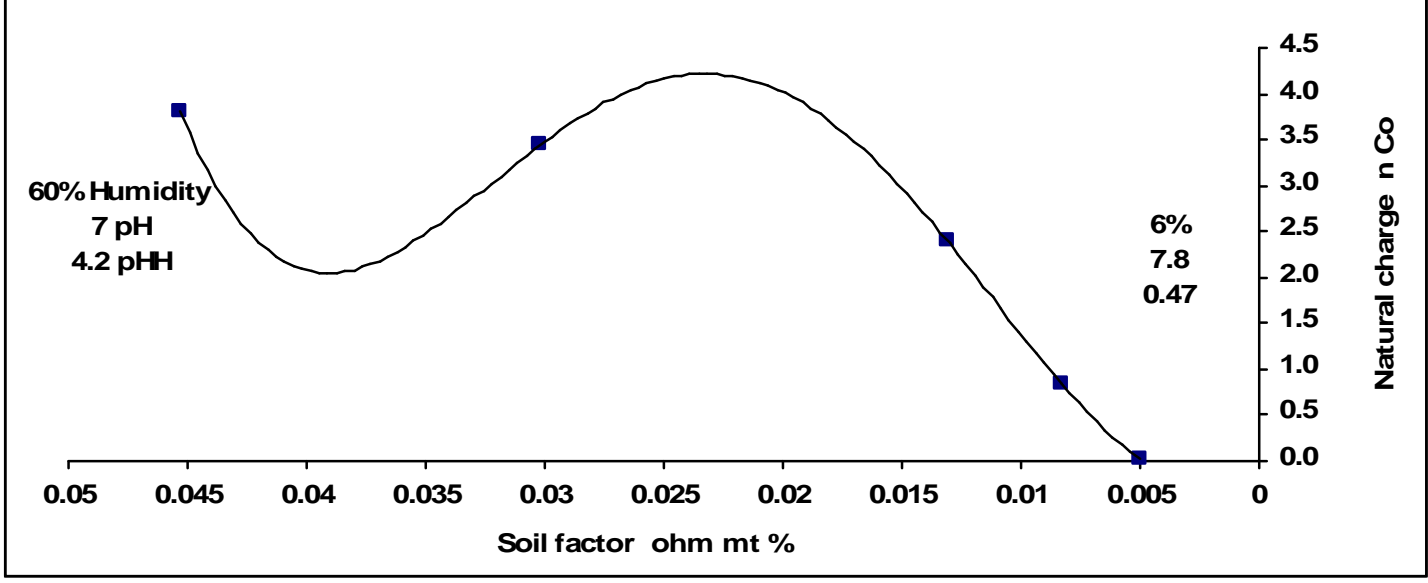

Figure 1: Natural prints of the electrical parameters for buried bare pipe-soil-earth of box 1 

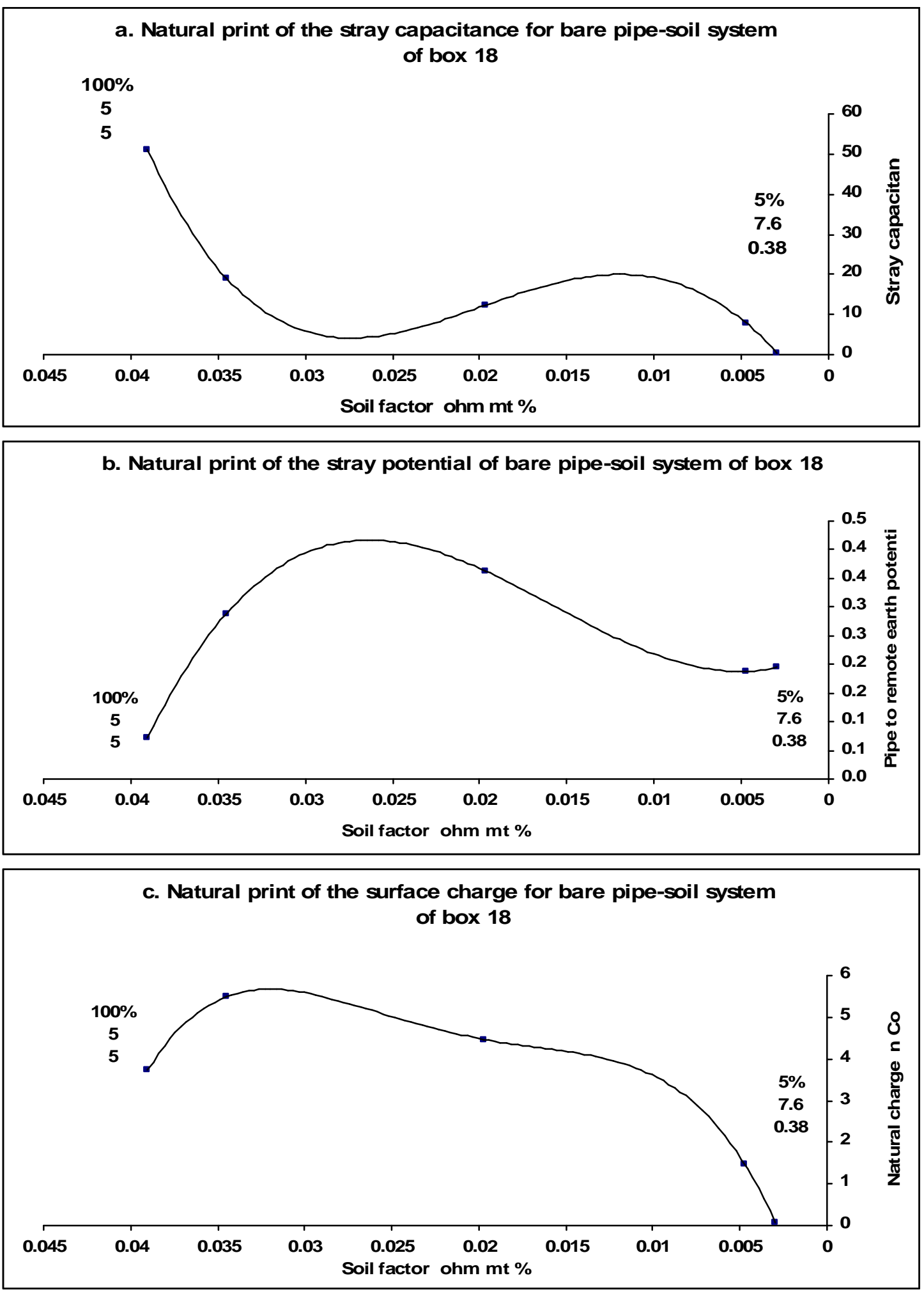

Figure 2: Natural prints of the electrical parameters for buried bare pipe-soil-earth of $\underline{\text { box } 18}$ 


\section{$\underline{2.5 \text { Surface Total Charge General Equation For Pipe - Soil - Earth Under Test }}$}

For each kind of soil under test and from the natural surface charge curves and equations, it can easily observe that the general equation of the surface charge, at natural condition without applying cathodic protection, is a $4^{\text {th }}$ degree polynomial equation which is function of the soil factor $Q_{N}=f(X=$ soil factor $)$. For each soil under test, the general surface natural charge equation is function of the measured soil factor, $\mathrm{Q}_{\mathrm{N}}=$ $\mathrm{f}\left(\mathrm{X}=\mathrm{S}_{\mathrm{f}}\right), 4^{\text {th }}$ degree polynomial. The surface natural charge general equation is equal to Eq. 4:

Where:

$$
\mathbf{Q}_{\mathrm{N}}=\mathrm{A}_{4 \mathrm{qn}} \mathbf{X}^{4}+\mathrm{A}_{3 \mathrm{qn}} \mathbf{X}^{\mathbf{3}}+\mathrm{A}_{2 \mathrm{qn}} \mathbf{X}^{\mathbf{2}}+\mathrm{A}_{1 \mathrm{qn}} \mathbf{X}+\mathrm{A}_{0 \mathrm{qn}}
$$

A's: = A ( ) q are the surface natural charge print constants of the pipe - soil under test $\mathbf{X}=$ is the value of the soil factor at certain humidity

\subsection{The Electrical Parameter General Equation Of Pipe-Soil-Earth System At Natural Condition Without Applying CP System}

We can observe clearly that the general form of any electrical parameter equation is function of the measured soil factor, $4^{\text {th }}$ degree polynomial but the A's print constants are different. From equations 2, 3 and 4, we can easily summarize the natural electrical parameters equations for the pipe-soil-earth under test, without applying cathodic protection system, as follow:

$$
\begin{aligned}
& \mathbf{C}_{\mathbf{n} \text { stray }}=\mathrm{A}_{4 \mathrm{cn}} \mathbf{X}^{4}+\mathrm{A}_{3 \mathrm{cn}} \mathbf{X}^{3}+\mathrm{A}_{2 \mathrm{cn}} \mathbf{X}^{\mathbf{2}}+\mathrm{A}_{1 \mathrm{cn}} \mathbf{X}+\mathrm{A}_{0 \mathrm{cn}} \\
& \mathbf{V}_{\mathbf{n} \text { stray }}=\mathrm{A}_{4 \mathrm{vn}} \mathbf{X}^{4}+\mathrm{A}_{3 \mathrm{vn}} \mathbf{X}^{3}+\mathrm{A}_{2 \mathrm{vn}} \mathbf{X}^{2}+\mathrm{A}_{1 \mathrm{vn}} \mathbf{X}+\mathrm{A}_{0 \mathrm{vn}} \\
& \mathbf{Q}_{\mathbf{n} \text { stray }}=\mathrm{A}_{4 \mathrm{qn}} \mathbf{X}^{4}+\mathrm{A}_{3 \mathrm{qn}} \mathbf{X}^{3}+\mathrm{A}_{2 \mathrm{qn}} \mathbf{X}^{2}+\mathrm{A}_{1 \mathrm{qn}} \mathbf{X}+\mathrm{A}_{0 \mathrm{qn}}
\end{aligned}
$$

We can observe clearly that the general form of any electrical parameter equation, at natural condition without applying cathodic protection, is function of the measured soil factor, $4^{\text {th }}$ degree polynomial but the A's PRINT constants are different. Then, the general form of any electrical parameters equation of the pipe-soil-earth system under test at natural condition without applying cathodic protection with the same amount of soil volume will be as shown by the following equation :

Natural electrical parameter of pipe-soil-earth system under test $=$

$$
\mathrm{A}_{4} \mathbf{X}^{4}+\mathrm{A}_{3} \mathbf{X}^{3}+\mathrm{A}_{2} \mathbf{X}^{2}+\mathrm{A}_{1} \mathbf{X}+\mathrm{A}_{0}
$$

The A's are obtained from the correspondent print table and

$\mathbf{X}$ is the measured soil factor 
The natural electric parameters general equation and PRINT curves show the following important results:

a) Buried pipe in a soil which generates the minimum natural created charge at bare pipe surface at normal steady humidity is defining the most suitable choice of soil to be around the pipe.

b) In case of space or vacuum is the medium which is surrounding the pipeline instead of soil medium, the value of the soil factor will be zero as $\mathrm{K}_{\mathrm{S}}=1, \mathrm{H}=$ $0 \%, \rho=$ infinity. That's to say that the natural created charge will equal to zero ( $A_{O}$ will equal to zero for pipe-vacuum system) which is the ideal case of corrosion prevention.

c) In case of air is the medium which is surrounding the pipeline instead of soil medium, the value of the soil factor will be smaller than that of the soil at same humidity as $\mathrm{K}_{\mathrm{S}} \approx 1$ (it is not almost that $\mathrm{K}_{\mathrm{S}} \approx 1$ if the humidity exists in air), $\mathrm{H}=$ $10 \%$ up to $60 \%$ or more, $\mathrm{pH}=7 \& \rho=$ value according to $\mathrm{H} \%$. Consequently, the natural created charge exists in air but with smaller amount than that of soil at same humidity. That's to say that air is most proper surrounding medium for a pipe than soil at same humidity condition.

\subsection{Natural Stray Potential Print Constants For Pipe-Soil-Earth Under Test}

Now, the natural stray potential print constants of the pipe-soil-earth system under test are $\mathrm{A}_{4 \mathrm{VN}}, \mathrm{A}_{3 \mathrm{VN}}, \mathrm{A}_{2 \mathrm{VN}}, \mathrm{A}_{1 \mathrm{VN}}$ and $\mathrm{A}_{0 \mathrm{VN}}$. This means that these print values are valid for these pipe-soil systems under test at any time at the correspondent electrochemical properties (soil factor). Table 3 shows result example of the natural stray potential print.

Table 3: PRINT constants of the stray potential for 10 different soil under test

\begin{tabular}{|c|c|c|c|c|c|c|c|c|c|c|}
\hline Soil & $\rho_{1}$ & $\boldsymbol{\rho}_{2}$ & $\rho_{3}$ & $\rho_{4}$ & $\rho_{5}$ & $\rho_{6}$ & $\rho_{7}$ & $\rho_{8}$ & $\rho_{9}$ & $\rho_{10}$ \\
\hline Error & 0 & $\pm 30 \%$ & 0 & 0 & 0 & 0 & 0 & 0 & 0 & 0 \\
\hline $\mathbf{A}_{4 \mathrm{VN}}$ & $\stackrel{-}{2 .}+06$ & 0 & 321339 & 5620 & 8822.1 & 0 & 118.12 & 140960 & 0 & 546856 \\
\hline $\mathbf{A}_{3 \mathrm{VN}}$ & 202688 & 698.68 & -78007 & $\begin{array}{c}- \\
3154.1 \\
\end{array}$ & $\begin{array}{c}- \\
3710.9 \\
\end{array}$ & $\begin{array}{c}- \\
48181 \\
\end{array}$ & $\begin{array}{c}- \\
153.09 \\
\end{array}$ & -37414 & $\begin{array}{c}- \\
110.64 \\
\end{array}$ & $\begin{array}{c}- \\
110280 \\
\end{array}$ \\
\hline $\mathbf{A}_{2 \mathrm{VN}}$ & $\begin{array}{c}- \\
6782.5 \\
\end{array}$ & $\begin{array}{c}- \\
157.71 \\
\end{array}$ & 6025.9 & 599.26 & 407.17 & 2278.7 & 54.029 & 3218.8 & 100.61 & 7753.7 \\
\hline $\mathbf{A}_{1 \mathrm{VN}}$ & 82.539 & 9.8253 & $\begin{array}{c}- \\
159.72 \\
\end{array}$ & $\begin{array}{c}- \\
44.958 \\
\end{array}$ & $\begin{array}{c}- \\
3.3452 \\
\end{array}$ & $\begin{array}{c}- \\
19.695 \\
\end{array}$ & $\begin{array}{c}- \\
3.1804 \\
\end{array}$ & $\begin{array}{c}- \\
99.254\end{array}$ & -24.97 & $\begin{array}{c}- \\
215.37 \\
\end{array}$ \\
\hline $\mathbf{A}_{\mathbf{0 V N}}$ & -0.133 & 0.0009 & 1.377 & 1.412 & 0.0954 & 0.2352 & 0.1245 & 0.9629 & 1.2357 & 1.8678 \\
\hline
\end{tabular}




\section{$\underline{\text { 2.8 Natural Stray Capacitance Print Constants For Pipe-Soil-Earth Under Test }}$}

Now, the stray capacitance print constants of the pipe-soil-earth system under test are $\mathrm{A}_{4 \mathrm{CN}}, \mathrm{A}_{3 \mathrm{CN}}, \mathrm{A}_{2 \mathrm{CN}}, \mathrm{A}_{1 \mathrm{CN}}$ and $\mathrm{A}_{0 \mathrm{CN}}$. This means that these print values are valid for these pipe-soil systems under test at any time at the correspondent electrochemical properties (the soil factor). Table 4 shows the natural stray capacitance print constants.

Table 4: PRINT constants of natural stray capacitance for 10 different soils under test

\begin{tabular}{|c|c|c|c|c|c|c|c|c|c|c|}
\hline Soil & $\boldsymbol{\rho}_{\mathbf{1}}$ & $\boldsymbol{\rho}_{\mathbf{2}}$ & $\boldsymbol{\rho}_{\mathbf{3}}$ & $\boldsymbol{\rho}_{\mathbf{4}}$ & $\boldsymbol{\rho}_{\mathbf{5}}$ & $\boldsymbol{\rho}_{\mathbf{6}}$ & $\boldsymbol{\rho}_{\mathbf{7}}$ & $\boldsymbol{\rho}_{\mathbf{8}}$ & $\boldsymbol{\rho}_{\mathbf{9}}$ & $\boldsymbol{\rho}_{\mathbf{1 0}}$ \\
\hline Error & 0 & $\pm 30 \%$ & 0 & 0 & $\pm 30 \%$ & 0 & 0 & 0 & 0 & 0 \\
\hline $\mathbf{A}_{\mathbf{4 C N}}$ & $1 . \mathrm{E}+08$ & 0 & - & $1 . \mathrm{E}+06$ & 0 & $6 . \mathrm{E}+07$ & 26675 & $\begin{array}{c}- \\
9 . \mathrm{E}+06\end{array}$ & 21770 & $1 . \mathrm{E}+07$ \\
\hline $\mathbf{A}_{\mathbf{3 C N}}$ & - & 262166 & $1 . \mathrm{E}+06$ & $\begin{array}{c}- \\
620109\end{array}$ & $\begin{array}{c}- \\
269270\end{array}$ & $4 . \mathrm{E}+06$ & -35297 & $2 . \mathrm{E}+06$ & $\begin{array}{c}- \\
16925\end{array}$ & $\begin{array}{c}- \\
1 . \mathrm{E}+06\end{array}$ \\
\hline $\mathbf{A}_{\mathbf{2 C N}}$ & 322980 & -47807 & -88692 & 99288 & 69267 & - & 13424 & - & 3178 & 21862 \\
\hline $\mathbf{A}_{\mathbf{1 C N}}$ & -1549 & 2428 & 2780 & -5207 & -1953 & 6969 & -1209 & 6766 & 120 & 874 \\
\hline $\mathbf{A}_{\mathbf{0 C N}}$ & 1.27 & -24.8 & -15.55 & 84 & 12.77 & -17 & 31 & -58 & -6 & -6.8 \\
\hline
\end{tabular}

\subsection{Surface Natural Charge Print Constants For Pipe-Soil-Earth Under Test}

Now, the surface natural charge print constants of the pipe-soil-earth system under test are $A_{4 q}, A_{3 q}, A_{2 q}, A_{1 q}$ and $A_{0 q}$. This means that these print values are valid for these pipe-soil systems under test at any time at the correspondent electrochemical properties (soil factor). Table 5 shows surface natural charge print constants.

Table 5: Natural charge PRINT at the pipe surface for 10 different soils under test

\begin{tabular}{|c|c|c|c|c|c|c|c|c|c|c|}
\hline Soil & $\rho_{1}$ & $\rho_{2}$ & $\rho_{3}$ & $\boldsymbol{\rho}_{4}$ & $\rho_{5}$ & $\rho_{6}$ & $\rho_{7}$ & $\rho_{8}$ & $\rho_{9}$ & $\rho_{10}$ \\
\hline Error & 0 & $\pm 50 \%$ & 0 & 0 & $\pm 25 \%$ & 0 & 0 & 0 & 0 & 0 \\
\hline $\mathbf{A}_{4 q n}$ & 3.E+07 & 0 & $\begin{array}{c}- \\
919280 \\
\end{array}$ & 526631 & 0 & $\begin{array}{c}- \\
4 . \mathrm{E}+07 \\
\end{array}$ & 9205.4 & $\begin{array}{c}- \\
376311 \\
\end{array}$ & $\begin{array}{c}- \\
9566.4 \\
\end{array}$ & $\begin{array}{c}- \\
715518 \\
\end{array}$ \\
\hline $\mathbf{A}_{3 q n}$ & 2. & 45298 & 242778 & $\begin{array}{c}- \\
267958\end{array}$ & $\begin{array}{c}- \\
26967\end{array}$ & 4.E+06 & $\begin{array}{c}- \\
12309\end{array}$ & 101374 & 9162.1 & 157730 \\
\hline $\mathbf{A}_{2 q n}$ & 60696 & -8408 & -20512 & 43238 & 6411 & -110112 & 4771.1 & -9536 & -2632 & -10306 \\
\hline$A_{1 q n}$ & -261 & 432.74 & 622.04 & -2329 & -41.27 & 1486.5 & -461.4 & 360.12 & 227.38 & 253 \\
\hline $\mathbf{A}_{\mathbf{0 q n}}$ & 0.1 & -4.46 & -3.368 & 38.55 & -1.36 & -3.463 & 12.625 & -3.27 & -4.63 & -1.168 \\
\hline
\end{tabular}




\section{Case 2:}

\subsection{Pipe - Soil - Earth System With applying Cathodic Protection System}

\subsubsection{The Experiment}

At natural condition system without any influence of any external systems such as cathodic protection systems, pipe crossing... (only bare pipe + soil + impressed current system + point earth), the experiment is consisting of a system with bare pipe segment $(2.1 \mathrm{~cm}$ diameter, $1 \mathrm{~mm}$ thickness and $31.1 \mathrm{~cm}$ length), buried in a soil with humidity equal to $10 \%$ and the soil have soil resistivity equal to $\rho$.m, soil power of hydrogen $\mathrm{pH}$ and soil relative permittivity $\mathrm{K}_{\mathrm{s}}$. The impressed current system is consisting of a nail as an anode which is connected to the positive terminal of variable d-c source while the negative terminal is connected to the bare pipe segment. Table 1 shows the different kind of soils used in this experiment and the range of humidity.

When considering the system pipe-soil-earth for ten different kind of soil as shown in table 1, the test procedures are as follow:

1) Calculate the value of the soil factor according to the Eq.1 :

2) Measure both the stray potential $V_{P-P E}$, the stray capacitance $C_{P-P E}$, the protection current $\mathrm{I}_{\mathrm{P}}$ and the correspondent pipe to soil potential $\mathrm{V}_{\mathrm{H}-\mathrm{C}}$ by using $\mathrm{Cu} / \mathrm{CuSO}_{4}$ half cell. Calculate total surface charge $\mathrm{Q}=\mathrm{V}_{\mathrm{P}-\mathrm{PE}} * \mathrm{C}_{\mathrm{P}-\mathrm{PE}}$

3) Increase the c.p protection current $I_{P}$

4) Repeat step $2 \& 3$ up to $V_{H-C}=-2$ volt

5) Increase the Humidity and calculate the new value of the soil factor.

6) Repeat steps $2,3 \& 4$ until humidity around the pipe segment reaches its maximum as shown in table 1.

7) Change this type of soil by another kind of soil and repeat all the steps done before.

8) Repeat again the steps for 10 different kind of soil as shown in table 1.

9) Build up the results table.

\section{$\underline{3.1 .2 \text { Results }}$}

If we plot the measured electric quantity (stray potential $V_{\mathrm{P}-\mathrm{PE} \text {, }}$ stray capacitance $\mathrm{C}_{\mathrm{P} \text { - }}$ ${ }_{\mathrm{PE}}$, surface total charge $\mathrm{Q}$ and protection current $\mathrm{I}_{\mathrm{P}}$ ) individually as y axis in terms of the correspondent measured soil factor as $\mathrm{x}$ axis at the correspondent different levels of pipe to soil potential $\mathrm{V}_{\mathrm{H}-\mathrm{C}}$ by using $\mathrm{Cu} / \mathrm{CuSO}_{4}$ half cell from $-0.2 \mathrm{v}$ to -2 volt, we will obtain such following curves as shown in figures 3, $4 \& 5$. Except box 4 and box 24 , the curves and equations of the electrical parameters show eight boxes which could be expressed by a $4^{\text {th }}$ degree polynomial equation with an error equal to zero percent. Table 6 shows the error table for the 10 different soil resistivity under test. 
Table 6: Average error table for 10 different kinds of soil and operating range of Humidity

\begin{tabular}{|c|c|c|c|c|c|c|c|c|c|c|c|}
\hline \multicolumn{2}{|c|}{ Soil } & $\rho_{1}$ & $\rho_{2}$ & $\rho_{3}$ & $\rho_{4}$ & $\rho_{5}$ & $\rho_{6}$ & $\rho_{7}$ & $\rho_{8}$ & $\rho_{9}$ & $\rho_{10}$ \\
\hline \multicolumn{2}{|c|}{ Box under test } & 1 & 4 & 9 & 10 & 13 & 18 & 19 & 24 & 27 & 28 \\
\hline \multicolumn{2}{|c|}{$\begin{array}{c}\text { Polynomial } \\
\text { degree }\end{array}$} & $4^{\text {th }}$ & $4^{\text {th }}$ & $4^{\text {th }}$ & $4^{\text {th }}$ & $4^{\text {th }}$ & $4^{\text {th }}$ & $4^{\text {th }}$ & $4^{\text {th }}$ & $4^{\text {th }}$ & $4^{\text {th }}$ \\
\hline \multicolumn{2}{|c|}{$\mathrm{V}_{\text {P-PE }}$ Error \% } & 0 & \pm 30 & 0 & 0 & 0 & 0 & 0 & \pm 30 & 0 & 0 \\
\hline \multicolumn{2}{|c|}{$\mathrm{C}_{\mathrm{P}-\mathrm{PE}}$ Error \% } & 0 & \pm 30 & 0 & 0 & 0 & 0 & 0 & \pm 30 & 0 & 0 \\
\hline \multicolumn{2}{|c|}{$\mathbf{Q}_{\text {тот. }}$ Error \% } & 0 & \pm 30 & 0 & 0 & 0 & 0 & 0 & \pm 30 & 0 & 0 \\
\hline \multicolumn{2}{|c|}{$\begin{array}{ll}\mathbf{I}_{\mathbf{P}} & \text { Error \% }\end{array}$} & 0 & \pm 30 & 0 & 0 & 0 & 0 & 0 & \pm 30 & 0 & 0 \\
\hline \multirow{2}{*}{$\begin{array}{c}\text { Humidity } \\
\%\end{array}$} & Start & 6 & 8 & 5 & 10 & 6 & 5 & 5 & 5 & 5 & 10 \\
\hline & End & 60 & 85 & 100 & 100 & 100 & 100 & 96 & 80 & 100 & 100 \\
\hline
\end{tabular}

\subsection{Stray Potential For Pipe-Soil-Earth Under Test}

From the stray potential PRINT curves and trend lines equations, it can easily observe that the general equation of the stray potential of a cathodically protected bare pipe segment during humidity change under multi level of cathodic protection levels is a $4^{\text {th }}$ degree polynomial equation which is function of the soil factor $\mathrm{V}_{\text {str. }}=\mathrm{f}(\mathrm{X}=$ soil factor $)$. For each soil under test, the general stray

potential equation is function of the measured soil factor, $V_{\text {Str. }}=f\left(X=S_{f}\right), 4^{\text {th }}$ degree polynomial. The stray potential general equation is equal to Eq. 5:

Where:

$$
\mathbf{V}_{\text {Str. }}=\mathrm{A}_{4 \mathrm{~V}} \mathbf{X}^{4}+\mathrm{A}_{3 \mathrm{~V}} \mathbf{X}^{3}+\mathrm{A}_{2 \mathrm{~V}} \mathbf{X}^{2}+\mathrm{A}_{1 \mathrm{~V}} \mathbf{X}+\mathrm{A}_{0 \mathrm{~V}}
$$

A's: $=\mathrm{A}()_{\mathrm{v}}$ are the stray potential print constants of the pipe - soil under test $\mathbf{X}=$ is the value of the soil factor at certain humidity

\section{$\underline{\text { 3.3 Stray Capacitance For Pipe-Soil-Earth Under Test }}$}

From the stray capacitance PRINT curves and trend lines equations, it can easily observe that the general equation of the stray capacitance of a cathodically protected bare pipe segment during humidity change under multi level of cathodic protection levels is a $4^{\text {th }}$ degree polynomial equation which is function of the soil factor $V_{\text {Str. }}=f(X$ $=$ soil factor), the same equation as that of pipe - soil - earth system without applying cathodic protection. For each soil under test, the general stray capacitance equation is 

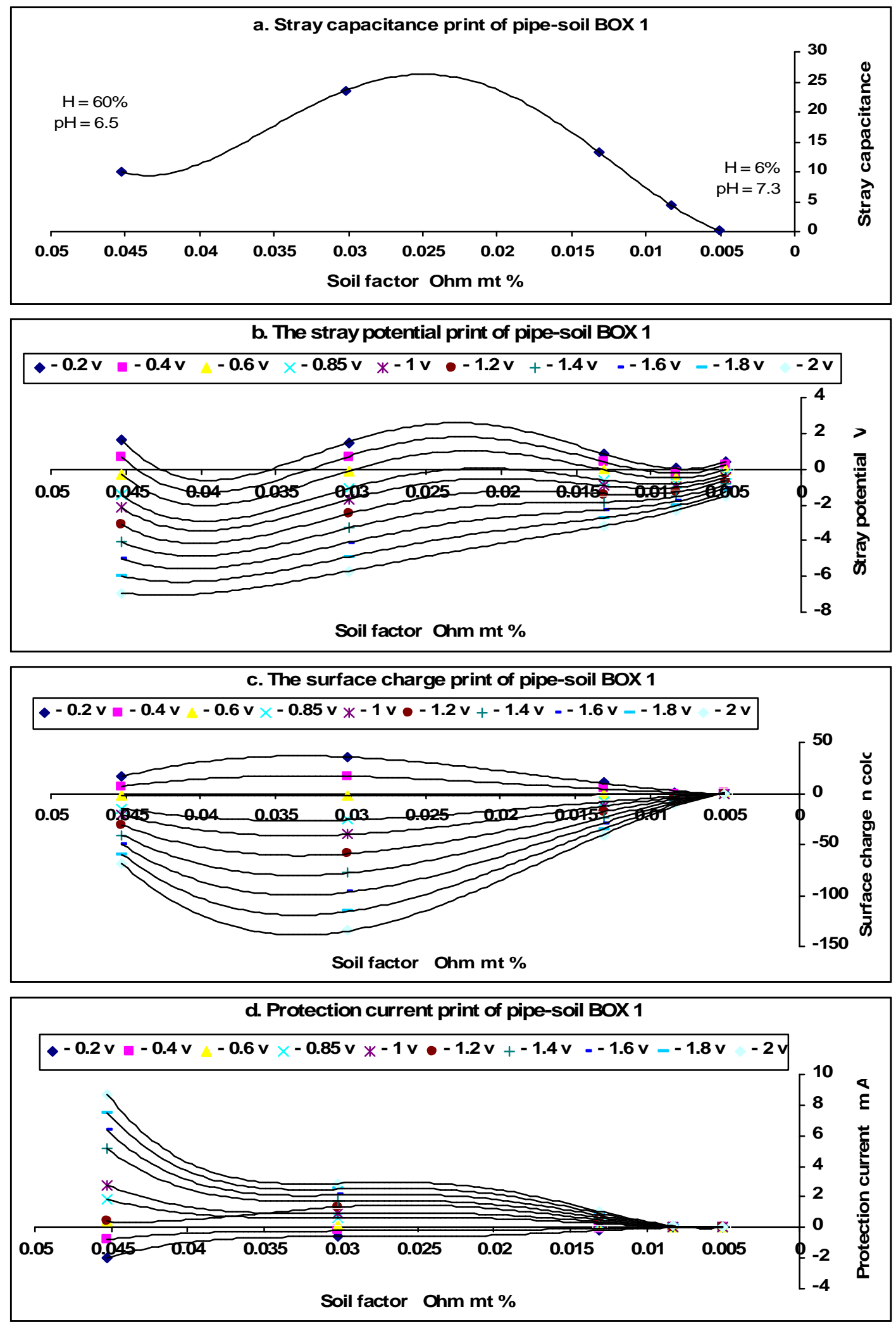

Figure 3: Electrical Parameters PRINT curves of pipe-soil-earth of BOX 1 

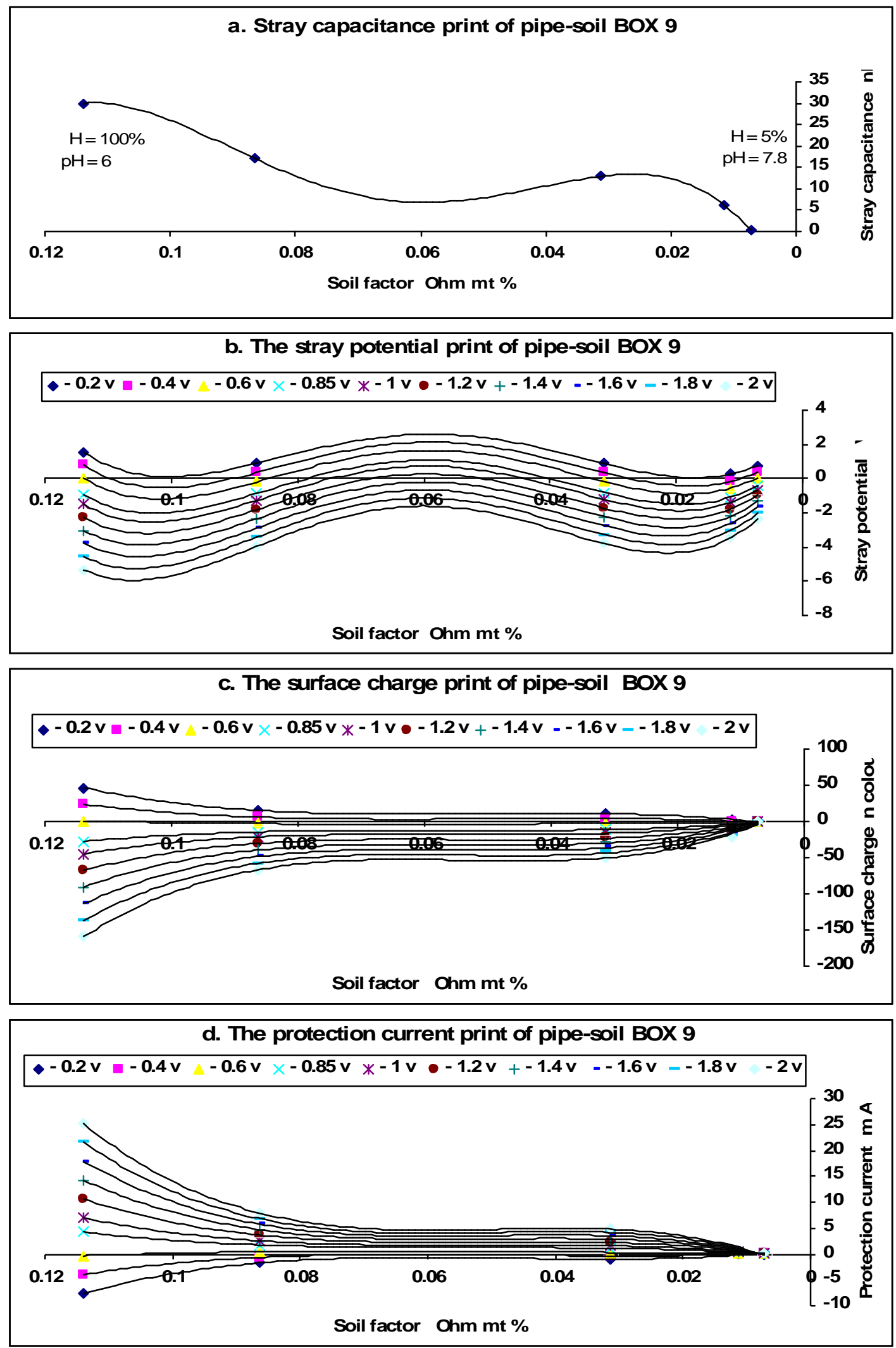

Figure 4: Electrical Parameters PRINT curves of pipe-soil-earth of BOX 9 

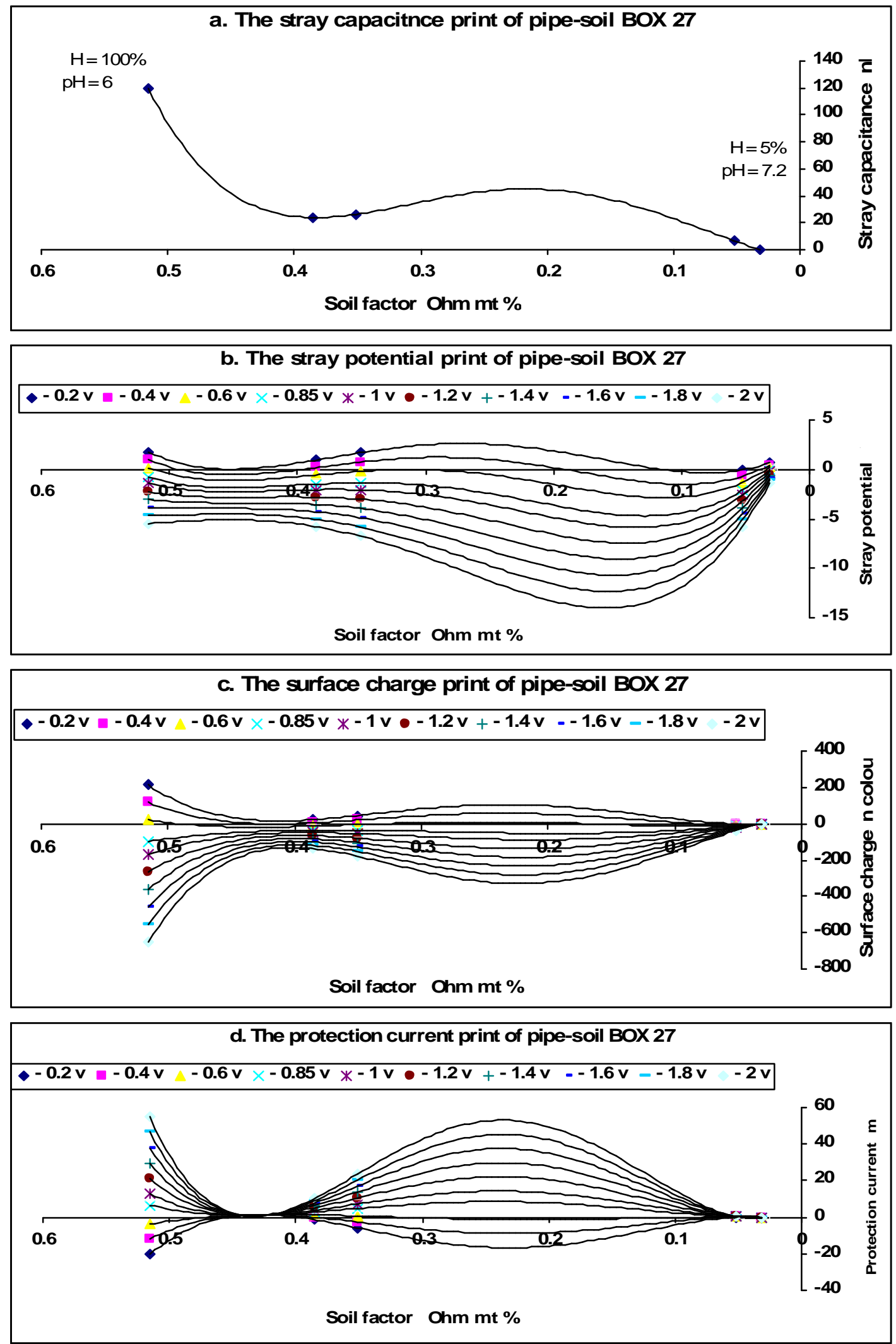

Figure 5: Electrical Parameters PRINT curves of pipe-soil-earth of BOX 27 
function of the measured soil factor, $\mathrm{C}_{\mathrm{Str} .}=\mathrm{f}\left(\mathrm{X}=\mathrm{S}_{\mathrm{f}}\right), 4^{\text {th }}$ degree polynomial. The stray potential general equation is equal to Eq. 6 :

Where:

$$
\mathbf{C}_{\text {Str. }}=\mathbf{C}_{\mathbf{n} \text { stray }}=\mathrm{A}_{4 \mathrm{cn}} \mathbf{X}^{\mathbf{4}}+\mathrm{A}_{3 \mathrm{cn}} \mathbf{X}^{\mathbf{3}}+\mathrm{A}_{2 \mathrm{cn}} \mathbf{X}^{\mathbf{2}}+\mathrm{A}_{1 \mathrm{cn}} \mathbf{X}+\mathrm{A}_{0 \mathrm{cn}}
$$

A's: $=\mathrm{A}()_{\mathrm{cn}}$ are the stray capacitance print constants of the pipe - soil under test

$\mathbf{X}=$ is the value of the soil factor at certain humidity

\subsection{Surface Total Charge For Pipe-Soil-Earth Under Test}

From the surface total charge PRINT curves and trend lines equations, it can easily observe that the general equation of the surface total charge of a cathodically protected bare pipe segment during humidity change under multi level of cathodic protection levels is a $4^{\text {th }}$ degree polynomial equation which is function of the soil factor $Q_{\text {tot. }}=f(X$ $=$ soil factor). For each soil under test, the general surface total charge equation is function of the measured soil factor, $Q_{\text {tot. }}=\mathrm{f}\left(\mathrm{X}=\mathrm{S}_{\mathrm{f}}\right), 4^{\text {th }}$ degree polynomial. The surface total charge general equation is equal to Eq. 7 :

Where:

$$
\mathbf{Q}_{\text {tot. }}=\mathrm{A}_{4 \mathrm{q}} \mathbf{X}^{4}+\mathrm{A}_{3 \mathrm{q}} \mathbf{X}^{3}+\mathrm{A}_{2 \mathrm{q}} \mathbf{X}^{2}+\mathrm{A}_{1 \mathrm{q}} \mathbf{X}+\mathrm{A}_{0 \mathrm{q}}
$$

A's: = A ( ) q are the surface total charge print constants of the pipe - soil under test

$\mathbf{X}=$ is the value of the soil factor at certain humidity

\section{$\underline{3.5 \text { Protection Current General Equation For Pipe - Soil - Earth Under Test }}$}

Definition: "The ONION curves are the curves of the protection current $I_{P}$ in terms of the soil factor $S_{\mathrm{f}}$ at different half cell voltage $\mathrm{V}_{\text {H.C }}$ levels". From the PRINT ONION curves and trend lines equations, it can easily observe that the general equation of the protection current of a cathodically protected bare pipe segment during humidity change under multi level of cathodic protection levels is a $4^{\text {th }}$ degree polynomial equation which is function of the soil factor, $I_{P}=f(X=$ soil factor $)$

For each soil under test, the general protection current equation is function of the measured soil factor $I_{P}=f\left(X=S_{f}\right), 4^{\text {th }}$ degree polynomial. The protection current general equation is equal to Eq. 8:

$$
\mathbf{I}_{\mathbf{P}}=\mathrm{A}_{4 \mathrm{I}} \mathbf{X}^{4}+\mathrm{A}_{3 \mathrm{I}} \mathbf{X}^{3}+\mathrm{A}_{2 \mathrm{I}} \mathbf{X}^{2}+\mathrm{A}_{1 \mathrm{I}} \mathbf{X}+\mathrm{A}_{0 \mathrm{I}}
$$


Where:

A's: $=\mathrm{A}_{() \mathrm{I}}$ are the protection current print constants of the pipe soil under test $\mathbf{X}=$ is the value of the soil factor at certain humidity

\subsection{The Electrical Parameter General Equation Of Pipe-Soil-Earth System With Applying C.P System}

We can observe clearly that the general form of any electrical parameter equation is function of the measured soil factor, $4^{\text {th }}$ degree polynomial but the A's constants are different and are dependant on the pipe to soil potential except the stray capacitance which is independent of the pipe to soil potential . From equations 5, 6, 7 and 8, we can easily summarize the electrical parameters trend lines equations for the pipe-soil-earth under test, with applying c.p system, are in the form as follow:

$$
\begin{aligned}
\mathbf{C}_{\text {stray }} & =A_{4 \mathrm{cn}} \mathbf{X}^{4}+\mathrm{A}_{3 \mathrm{cn}} \mathbf{X}^{3}+\mathrm{A}_{2 \mathrm{cn}} \mathbf{X}^{2}+\mathrm{A}_{1 \mathrm{cn}} \mathbf{X}+\mathrm{A}_{0 \mathrm{cn}} \\
\mathbf{V}_{\text {stray }} & =\mathrm{A}_{4 \mathrm{v}} \mathbf{X}^{4}+\mathrm{A}_{3 \mathrm{v}} \mathbf{X}^{3}+\mathrm{A}_{2 \mathrm{v}} \mathbf{X}^{2}+\mathrm{A}_{1 \mathrm{v}} \mathbf{X}+\mathrm{A}_{0 \mathrm{v}} \\
\mathbf{Q}_{\text {stray }} & =\mathrm{A}_{4 \mathrm{q}} \mathbf{X}^{4}+\mathrm{A}_{3 \mathrm{q}} \mathbf{X}^{3}+\mathrm{A}_{2 \mathrm{q}} \mathbf{X}^{2}+\mathrm{A}_{1 \mathrm{q}} \mathbf{X}+\mathrm{A}_{0 \mathrm{q}} \\
\mathbf{I}_{\mathbf{P}} & =\mathrm{A}_{4 \mathrm{IP}} \mathbf{X}^{4}+\mathrm{A}_{3 \mathrm{IP}} \mathbf{X}^{3}+\mathrm{A}_{2 \mathrm{IP}} \mathbf{X}^{2}+\mathrm{A}_{1 \mathrm{IP}} \mathbf{X}+\mathrm{A}_{0 \mathrm{IP}}
\end{aligned}
$$

Then, the general form of any electrical parameters equation of the pipe-soil-earth

\begin{tabular}{|c|}
\hline $\begin{array}{l}\text { Electrical parameter of pipe-soil-earth system under test } \\
\qquad \mathrm{A}_{4} \mathbf{X}^{4}+\mathrm{A}_{3} \mathbf{X}^{3}+\mathrm{A}_{2} \mathbf{X}^{2}+\mathrm{A}_{1} \mathbf{X}+\mathrm{A}_{0}\end{array}$ \\
\hline $\begin{array}{l}\text { The A's are obtained from the correspondent print table } \\
\text { and } \\
\qquad \mathbf{X} \text { is the measured soil factor }\end{array}$ \\
\hline
\end{tabular}
system under test, with applying cathodic protection, will be as shown in the following general equation which is the same as that of the system without applying cathodic protection:

\subsection{Stray Potential Print Constants For Pipe-Soil-Earth Under Test}

Now, the stray potential PRINT constants of the pipe-soil-earth systems under test are $\mathrm{A}_{4 \mathrm{~V}}, \mathrm{~A}_{3 \mathrm{~V}}, \mathrm{~A}_{2 \mathrm{~V}}, \mathrm{~A}_{1 \mathrm{~V}}$ and $\mathrm{A}_{0 \mathrm{~V}}$ at a definite cathodic protection level. This means that these 
print values are valid for these $\mathrm{CP}$ levels for these pipe soil systems under test at any time at the correspondent electrochemical properties (the soil factor). Table 7 shows result example of the stray potential print constants at $\mathrm{CP}$ level equal to -0.85 volt.

Table 7: Stray potential finger print constants at pipe to soil potential equal to -0.85 volt

\begin{tabular}{|c|c|c|c|c|c|c|c|c|c|c|}
\hline \multirow{2}{*}{$\mathrm{BOX}$} & $\boldsymbol{\rho}_{\mathbf{1}}$ & $\boldsymbol{\rho}_{\mathbf{2}}$ & $\boldsymbol{\rho}_{\mathbf{3}}$ & $\boldsymbol{\rho}_{\mathbf{4}}$ & $\boldsymbol{\rho}_{\mathbf{5}}$ & $\boldsymbol{\rho}_{\mathbf{6}}$ & $\boldsymbol{\rho}_{\mathbf{7}}$ & $\boldsymbol{\rho}_{\mathbf{8}}$ & $\boldsymbol{\rho}_{\mathbf{9}}$ & $\boldsymbol{\rho}_{\mathbf{1 0}}$ \\
\cline { 2 - 12 } & 1 & 4 & 9 & 10 & 13 & 18 & 19 & 24 & 27 & 28 \\
\hline $\mathbf{A}_{\mathbf{4 V}}$ & $3.00 \mathrm{E}+07$ & 0 & 925051 & 17354 & 1149.5 & $7.00 \mathrm{E}+07$ & 861.17 & 0 & 2228.7 & $1.00 \mathrm{E}+06$ \\
\hline $\mathbf{A}_{\mathbf{3 V}}$ & - & - & - & - & - & - & - & 61.62 & - & -194014 \\
\hline $\mathbf{A}_{\mathbf{2 V}}$ & $3.00 \mathrm{E}+06$ & 1858.9 & 223313 & 9862.3 & 4002.1 & $7.00 \mathrm{E}+06$ & 1531.8 & & 2755.3 & \\
\hline $\mathbf{A}_{\mathbf{1 V}}$ & -1023 & -37.7 & -428 & -143 & -176.7 & -2389.4 & -204.8 & 35.484 & -179.3 & -321.02 \\
\hline $\mathbf{A}_{\mathbf{0 V}}$ & 2.9327 & -0.61 & 1.9 & 2.6 & 2.37 & 4.66 & 7.154 & -2.19 & 4.49 & 1.6 \\
\hline Error & 0 & $\pm 30 \%$ & 0 & 0 & 0 & 0 & 0 & $\pm 30 \%$ & 0 & 0 \\
\hline
\end{tabular}

\subsection{Stray Capacitance Print Constants For Pipe-Soil-earth Under Test}

The stray capacitance PRINT constants of the pipe-soil-earth systems under test are $\mathrm{A}_{4 \mathrm{C}}, \mathrm{A}_{3 \mathrm{C}}, \mathrm{A}_{2 \mathrm{C}}, \mathrm{A}_{1 \mathrm{C}}$ and $\mathrm{A}_{0 \mathrm{C}}$ at any cathodic protection level. This means that these print values are valid at any CP levels for these pipe-soil systems under test at any time at the correspondent electrochemical properties (the soil factor). Table 8 shows the stray capacitance print constants at all CP levels.

Table 8: Stray capacitance print constants at any pipe to soil potential

\begin{tabular}{|c|c|c|c|c|c|c|c|c|c|c|}
\hline & $\rho_{1}$ & $\rho_{2}$ & $\rho_{3}$ & $\rho_{4}$ & $\rho_{5}$ & $\rho_{6}$ & $\rho_{7}$ & $\rho_{8}$ & $\rho_{9}$ & $\rho_{10}$ \\
\hline BOX & 1 & 4 & 9 & 10 & 13 & 18 & 19 & 24 & 27 & 28 \\
\hline $\mathbf{A}_{4 C}$ & $1 \mathrm{E}+08$ & 0 & $\begin{array}{c}- \\
4 \mathrm{E}+06 \\
\end{array}$ & $1 \mathrm{E}+06$ & 0 & $6 \mathrm{E}+07$ & 26675 & $\begin{array}{c}- \\
9 \mathrm{E}+06\end{array}$ & 21770 & $1 \mathrm{E}+07$ \\
\hline $\mathbf{A}_{3 \mathrm{C}}$ & $\begin{array}{c}- \\
1 \mathrm{E}+07 \\
\end{array}$ & 262166 & $1 \mathrm{E}+06$ & $\begin{array}{c}- \\
620109 \\
\end{array}$ & $\begin{array}{c}- \\
269270 \\
\end{array}$ & $4 \mathrm{E}+06$ & $\begin{array}{c}- \\
35297 \\
\end{array}$ & $2 \mathrm{E}+06$ & $\begin{array}{c}- \\
16925 \\
\end{array}$ & $\begin{array}{c}- \\
1 \mathrm{E}+06\end{array}$ \\
\hline $\mathbf{A}_{2 \mathrm{C}}$ & 322980 & -47807 & $\begin{array}{c}- \\
88692 \\
\end{array}$ & 99288 & 69267 & $\begin{array}{c}- \\
379156 \\
\end{array}$ & 13424 & $\begin{array}{c}- \\
203776 \\
\end{array}$ & 3178 & 21862 \\
\hline $\mathbf{A}_{1 \mathrm{C}}$ & -1549 & 2428 & 2781 & -5207 & -1953 & 6970 & -1209 & 6766 & 120.2 & 874.8 \\
\hline $\mathbf{A}_{\mathbf{0 C}}$ & 1.27 & -24.8 & -15.5 & 84.15 & 12.77 & -17.1 & 31.27 & -58.51 & -6 & -6.82 \\
\hline Error & 0 & $\pm 30 \%$ & 0 & 0 & $\pm 30 \%$ & 0 & 0 & 0 & 0 & 0 \\
\hline
\end{tabular}




\subsection{Surface Total Charge Print Constants For Pipe-Soil Under Test}

The surface total charge PRINT constants of the pipe-soil-earth systems under test are $\mathrm{A}_{4 \mathrm{q}}, \mathrm{A}_{3 \mathrm{q}}, \mathrm{A}_{2 \mathrm{q}}, \mathrm{A}_{1 \mathrm{q}}$ and $\mathrm{A}_{0 \mathrm{q}}$ at a definite cathodic protection level. This means that these print values are valid for these $\mathrm{CP}$ levels for these pipe soil systems under test at any time at the correspondent electrochemical properties (the soil factor). Table 9 shows result example of the surface total charge print constants at $\mathrm{CP}$ level equal to -0.85 volt.

Table 9: Print constants of the surface total charge at pipe to soil potential equal to - -0.85 volt

\begin{tabular}{|c|c|c|c|c|c|c|c|c|c|c|}
\hline & $\boldsymbol{\rho}_{\mathbf{1}}$ & $\boldsymbol{\rho}_{\mathbf{2}}$ & $\boldsymbol{\rho}_{\mathbf{3}}$ & $\boldsymbol{\rho}_{\mathbf{4}}$ & $\boldsymbol{\rho}_{\mathbf{5}}$ & $\boldsymbol{\rho}_{\mathbf{6}}$ & $\boldsymbol{\rho}_{\mathbf{7}}$ & $\boldsymbol{\rho}_{\mathbf{8}}$ & $\boldsymbol{\rho}_{\mathbf{9}}$ & $\boldsymbol{\rho}_{\mathbf{1 0}}$ \\
\cline { 2 - 12 } & 1 & 4 & 9 & 10 & 13 & 18 & 19 & 24 & 27 & 28 \\
\hline $\mathbf{A}_{\mathbf{4 q}}$ & 0 & 0 & $6 \mathrm{E}+06$ & 50596 & 0 & $5 \mathrm{E}+08$ & -11047 & 0 & -5597 & $-9 \mathrm{E}+06$ \\
\hline $\mathbf{A}_{\mathbf{3 q}}$ & $1 \mathrm{E}+06$ & -303338 & $-1 \mathrm{E}+06$ & -36942 & 57793 & $-6 \mathrm{E}+07$ & 12317 & -22910 & 135.97 & 980353 \\
\hline $\mathbf{A}_{\mathbf{2 q}}$ & -70717 & 57990 & 119052 & 8379 & -9785 & $2 \mathrm{E}+06$ & -2698 & 3326.1 & 2662 & -12884 \\
\hline $\mathbf{A}_{\mathbf{1 q}}$ & -84.36 & -3046 & -3394 & -846 & -857 & -24242 & -460 & -120 & -881.7 & -922.4 \\
\hline $\mathbf{A}_{\mathbf{0 q}}$ & 1.71 & 31.3 & 18.7 & 19.6 & 18.61 & 55.6 & 28.1 & -6.62 & 25 & 7 \\
\hline Error & 0 & $50 \%$ & 0 & 0 & $15 \%$ & 0 & 0 & $50 \%$ & 0 & 0 \\
\hline
\end{tabular}

\subsection{Protection current Print Constants For Pipe-Soil Under Test}

The protection current PRINT constants of the pipe-soil-earth systems under test are $\mathrm{A}_{4 \mathrm{I}}, \mathrm{A}_{3 \mathrm{I}}, \mathrm{A}_{2 \mathrm{I}}, \mathrm{A}_{1 \mathrm{I}}$ and $\mathrm{A}_{0 \mathrm{I}}$ at a definite cathodic protection level. This means that these print values are valid for these $\mathrm{CP}$ levels for these pipe-soil systems under test at any time at the correspondent electrochemical properties (the soil factor). Table 10 shows result example of the protection current print constants at $\mathrm{CP}$ level equal to -0.85 volt.

Table 10: The PRINT constants of the pipe current at pipe to soil potential equal to -0.85 volt

\begin{tabular}{|c|c|c|c|c|c|c|c|c|c|c|}
\hline & $\rho_{1}$ & $\rho_{2}$ & $\rho_{3}$ & $\rho_{4}$ & $\rho_{5}$ & $\rho_{6}$ & $\rho_{7}$ & $\rho_{8}$ & $\rho_{9}$ & $\rho_{10}$ \\
\hline $\mathrm{BOX}$ & 1 & 4 & 9 & 10 & 13 & 18 & 19 & 24 & 27 & 28 \\
\hline $\mathbf{A}_{4 I}$ & $7 E+06$ & 0 & 14928 & 32198 & $\begin{array}{c}- \\
452755\end{array}$ & $\begin{array}{c}- \\
1 \mathrm{E}+07\end{array}$ & -206.1 & 23296 & 4596.1 & $4.00 \mathrm{E}+06$ \\
\hline $\mathbf{A}_{3 \mathrm{I}}$ & $\begin{array}{c}- \\
636953\end{array}$ & -6223 & 9231 & $\begin{array}{c}- \\
16158\end{array}$ & 216364 & 906336 & 296.1 & 1329 & -4409 & -617139 \\
\hline$\overline{A_{2 I}}$ & 17742 & 1138.7 & -1749 & 2569 & -30555 & -25814 & -118 & -596.9 & 1202 & 26816 \\
\hline $\mathbf{A}_{1 I}$ & -148.8 & -25.2 & 99.9 & -129 & 1139 & 371 & 12.56 & 47.3 & -66.9 & -345.4 \\
\hline $\mathbf{A}_{0 I}$ & 0.4 & 0.2 & -0.62 & 2 & -11.77 & -0.88 & -0.37 & -0.5 & 1.1 & 1.34 \\
\hline Error & 0 & $30 \%$ & 0 & 0 & 0 & 0 & 0 & 0 & 0 & 0 \\
\hline
\end{tabular}




\section{Conclusion:}

The behavior of the electrical parameters (stray potential $\mathrm{V}_{\mathrm{P} \text {-PE, }}$ stray capacitance $\mathrm{C}_{\mathrm{P}-\mathrm{PE}}$, surface total charge $\mathrm{Q}$ and protection current $\mathrm{I}_{\mathrm{P}}$ ) of the pipe-soil-earth system, during the change of the electrochemical properties of the soil, with and without applying cathodic protection system, could be plotted as an electrical parameter PRINT which will be always valid in all times as the pipe-soil system is maintained and without any external interference. Once the system is changed by replacement another pipe with different dimension and/or the replacement of the soil, there will be another new electrical parameter PRINT for the new pipe-soil-earth system. Also, after completing electrical studies of pipe-soil-earth system in the near future, the buried pipe line segment with soil surrounding medium could be simulated electrically by an electric circuit where the system is subjected to the law: $(\mathrm{Q}=\mathrm{C} \times \mathrm{V})$ between the pipe surface and remote earth. This is where each of circuit electric parameter could be obtained by an equation as a function of the measured electrochemical properties of the soil (soil factor), $4^{\text {th }}$ degree polynomial at room temperature but the A's constants are different for each electric quantity .The constants of each equation (A's) considered to be as a PRINT of such pipesoil-earth system and valid until pipe and/or soil is changed with of course new print values. For buried bare pipe segments in different kind of soils with and without applying cathodic protection level, the PRINTS of the electrolytic stray capacitor between pipe \& earth, the stray potential across the stray capacitance, surface charge and the protection current of the cathodic protection system passed through the pipe segment were obtained in terms of the new parameter, the soil factor. The useful of these PRINTS is to obtain complete electrical data correlated with many cathodic protection levels which help, after complete erection of the pipeline, in defining the c.p level of any pipe line segment through its length by measuring the protection current and calculating the soil factor at the pipe segment from direct field measurements. The average error of the electrical parameters equations reduced to be less than $\pm 5 \%$. The most important advantage of such prospective electrical analogue circuit of pipe-soil-earth system is the possibility to simulate a complete pipeline - soil system by an electric circuit and to convert the corrosion problem and cathodic protection of the pipeline to an electric problem. In the near future after completing such electrical studies of the pipe-soil-earth systems, this will help in corrosion monitoring and the maintenance of c.p systems.

\section{Acknowledgement:}

First and foremost, thanks to GOD the most kind, the most merciful and to whom any success is related. 
Proceedings of the $7^{\text {th }}$ ICEENG Conference, 25-27 May, 2010

\section{References:}

1. Ashraf Abdelraouf M. Fouad Ahmed, A Proposed Systematic Concept to Evaluate the Performance of Cathodic Protection of Buried Pipe Line in the Soil, The Egyptian Society of Chemical Engineers, TESCE, Cairo, Egypt, 2003

2. Ashraf Abdelraouf M. Fouad Ahmed, A Proposed Systematic Concept to Evaluate the Performance of Cathodic Protection of Buried Pipe Line in the Soil, International conference "Future Vision and Challenges for Urban Development", HBRC Cairo, Egypt, 2004

3. Ashraf Abdelraouf M. Fouad Ahmed, The General Equation of the Natural Stray Capacitance between External Surface of Bare Pipe Segment and Earth, $25^{\text {th }}$ Annual Conference Corrosion Problems In Industry, ECS 2006.

4. Ashraf Abdelraouf M. Fouad Ahmed, The General Equation of the Natural Potential between External Surfaces of Bare Pipe Segment to Earth, $25^{\text {th }}$ Annual Conference Corrosion Problems In Industry, ECS 2006.

5. Ashraf Abdelraouf M. Fouad Ahmed, Deduction of The Natural Created Charge General Equation For A Buried Bare Pipe Line In The Soil, 25 ${ }^{\text {th }}$ Annual Conference Corrosion Problems In Industry, ECS 2006.

6. Ashraf Abdelraouf M. Fouad Ahmed, The General Equation and The Print Curves of The Stray Potential of a Cathodically Protected Buried Bare Pipe Segment, Ain- Shams University third international conference on environmental engineering, Ain-Shams University, ASCEE-3, 2009.

7. Ashraf Abdelraouf M. Fouad Ahmed, The General Equation and The Print Curves of The Stray Capacitance of a Cathodically Protected Buried Bare Pipe Segment, Ain-Shams University, ASCEE-3, 2009.

8. Ashraf Abdelraouf M. Fouad Ahmed, The General Equation and The Print Curves of The Total Surface Charge of a Cathodically Protected Buried Bare Pipe Segment, Ain-Shams University, ASCEE-3, 2009.

9. Ashraf Abdelraouf M. Fouad Ahmed, The General Equation and The Print Curves of The Net Current Flow of a Cathodically Protected Buried Bare Pipe Segment, Ain- Shams University, ASCEE-3, 2009. 